\title{
Optimization of flexographic print properties on ecologically favorable paper substrates
}

\section{ABSTRACT}

Nowadays, the attention in many industries is shifting towards the problem of waste overproduction and production of the waste in general. This study aimed to find an alternative approach to the production of packaging which will be environmentally friendly and at the same time optimal in terms of the print quality. This was accomplished by using the minimal needed amount of material for the production of packaging and adjusting the parameters of the flexographic printing process to achieve the desired visual impression of the print. The designed motive for the packaging was printed on five different recycled papers, following the guidelines of sustainable design. Printing was performed on each recycled paper with different printing pressures $(50 \mathrm{~N}, 150 \mathrm{~N}$, and $400 \mathrm{~N})$. Smoothness was measured on each paper; and for every printed sample, colorimetric measurements and thickness of the lines in positive and negative were measured. Print contrast for each print was calculated, and microscopy of fine printed elements was performed. All chosen papers except one had average smoothnes of up to $3.2 \mathrm{~s}$ (the smoothest paper had the average smootheness value of $54.72 \mathrm{~s}$ ). Smoothness results influenced the printed line widths. Specifically, when increasing the printing pressure, a significant deformation of the line width has occured on all papers except the smoothest one (deformations of the lines printed in positive were up to $400 \mu \mathrm{m}$ for rough papers compared to maximum of $60 \mu \mathrm{m}$ for lines printed on the smoother paper). Similar results were obtained for the lines printed in negative. Furthermore, legibility of the printed typographic elements of $4 \mathrm{pt}$ size was significantly influenced by the smoothness of the paper. Elements printed on the smoothest paper have displayed the negligible deformations when changing the printing pressure. For other papers, elements in positive were optimally printed by $50 \mathrm{~N}$ pressure, and elements in negative by the pressure of $400 \mathrm{~N}$. The results of this research have enabled the optimization of the flexographic printing process when using each of the five types of recycled papers. Furthermore, the presented qualitative and colorimetric parameters of the prints enabled the assessment of the applicability of used papers as printing substrates for ecologically favorable packaging.

\author{
Tamara Tomašegović \\ Jesenka Pibernik \\ Sanja Mahović Poljaček \\ Anđela Madžar \\ University of Zagreb, \\ Faculty of Graphic Arts, \\ Zagreb, Croatia
}

Corresponding author: Tamara Tomašegović e-mail: ttomaseg@grf.hr

First received: 14.10.2020. Accepted: 14.01.2021.

\section{KEY WORDS}

Recycled paper, flexography, printing pressure, colorimetry, line width

\section{Introduction}

The packaging is nowadays a fast-growing and fast-developing area in graphic technology. Special attention when designing the packaging product and choosing the materials for the packaging is being given to the ecological aspect of the final product. The principle of sustainable packaging is emphasizing the need for the usage of ecologically favorable materials (Dahlbo et al., 2018; Kaiser, Schmid \& Schlummer, 2017). This includes biodegradable and recycled materials (Moustafa et al., 2019; Marrez, Abdelhamid \& Darwesh, 2019). Further- 
more, the printing process should require a minimal amount of toxic chemicals. For example, printing plates used in the reproduction should be produced without using harmful compounds such as developing agents, and the usage of ecologically harmful printing inks should be avoided whenever possible (Tomašegović et al., 2020; Izdebska, Żołek-Tryznowska. \& Świętoński, 2015). Printing substrates for packaging that are eco-friendly are made of recycled and/or biodegradable materials such as recycled (and uncoated) papers, cellophane, PLA, PCL, and other polymeric materials (Ivanković et al., 2017; Mohamed \& Yusoh, 2015; Mraović et al., 2014; Pivnenko, Eriksson and Astrup, 2014). The potential issues which occur when printing on eco-friendly substrates, especially recycled papers are printability and the quality of the print (El-Sherif et al., 2019; Aydemir, 2016). Since recycled papers are usually not coated, the absorptivity and roughness of the substrate can cause problems with the ink spreading, absorption, and consequently the inability to print fine elements such as thin lines and small font sizes (Bates et al., 2020; Miljković, Valdec \& Matijević, 2018). Furthermore, many recycled papers have their specific shade which influences the colorimetric properties of the printed ink. Therefore, color deviations from the original ink color can be noticeable and even decrease the contrast between the substrate and printing ink, causing illegibility.

This research aimed to optimize the flexographic printing process used for printing on different recycled papers. Flexography was chosen as a printing technique because the elastomeric printing plate can adjust to rough printing substrates (Tomašegović et al., 2016). The process of the printing plate production can be aligned with ecological guidelines by using the laser-engraved EPDM printing plate and eliminating the need for harmful solvents. Modification of the printing pressure and analysis of the qualitative properties of the print on each recycled paper resulted in the recommendations for the application of used paper for specific types of motives on the packaging.

\section{Experimental}

\section{Materials and methodology}

To respect the sustainable design and ecological favourability of the packaging production, five different recycled paper was used as a printing substrate for packaging (Figure 1). The properties of each paper are listed in Table 1.

Papers were cut to samples of $5 \times 70 \mathrm{~cm}$ and conditioned 24 hours before printing. The printing process was carried out using IGT Printability Tester F1 (IGT Testing Systems, 2016) in the laboratory, at a relative humidity of $55 \%$ and $23{ }^{\circ}$ C.Anilox roller of $140 \mathrm{l} / \mathrm{cm}$ and $7.5 \mathrm{ml} / \mathrm{m}^{2}$ was used. Anilox pressure was set to $300 \mathrm{~N}$, and printing speed was set to $0.3 \mathrm{~m} / \mathrm{s}$. UV-curable ink, Pantone 363 $U$ was used. Printing pressure was varied in the printing process - it was set to $50 \mathrm{~N}, 150 \mathrm{~N}$, and $400 \mathrm{~N}$. In that way, 3 sets of printed samples were obtained for each paper. In the reproduction process, the ethylene propylene diene monomer (EPDM) printing plate was used. The production of the EPDM printing plate does not include any solvents, since the image is transferred to the printing plate utilizing laser engraving, without any developing processes (Wienke et al., 2020).

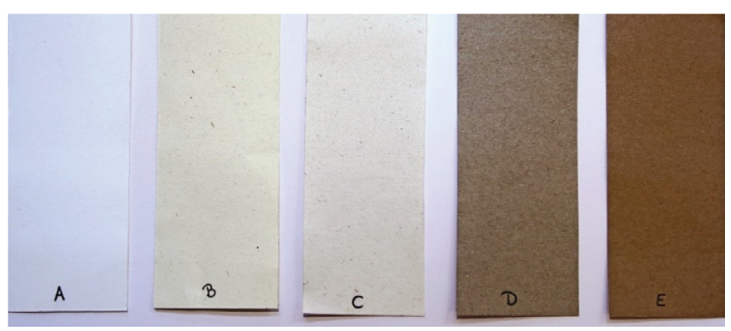

„ Figure 1: Recycled papers used as a printing substrate

\section{Table 1}

Grammage of the recycled papers used in the research

\begin{tabular}{c|c|c|c|c|c}
\hline & A & B & C & D & E \\
\hline Brand & MOHAWK & FLORA & FLORA & SCHOELLERS & SCHOELLERS \\
\hline $\begin{array}{c}\text { Grammage } \\
\left(\mathbf{g} / \mathbf{m}^{\mathbf{2}}\right)\end{array}$ & 220 & 130 & 100 & 140 & 140 \\
\hline
\end{tabular}

The smoothness of the paper was measured ten times on each sample according to Bekk method on a PTILine Bekk device. The smoothness test was carried out according to TAPPI standard T 479. Samples were placed on the glass plate, above which the measuring head is located. The measuring head pressed the sample with a weight of $10 \mathrm{~kg}$. The vacuum pump adjusted the air tank to a target pressure of $50.7 \mathrm{kPa}$. Depending on the smoothness of the test sample, the air remaining between the paper surface and the glass plate was transferred to the tank, until the pressure dropped to $48.0 \mathrm{kPa}$. The time it takes for the air volume of $10 \mathrm{~mL}$ to achieve a pressure of $48.0 \mathrm{kPa}$ provided the smoothness value expressed in seconds. A longer time indicates a smoother surface (Cigula, Tomašegović \& Hudika, 2019).

Colorimetric measurements were performed employing an X-rite eXact spectrophotometer (X-Rite, 2018). Measurements were performed 10 times on different parts of each printed sample, with the measurement conditions set to illuminant D50, a standard observer of $2^{\circ}$ and filter M1. CIE L*, a*, and $b^{*}$ coordinates were measured on full-tone patches on each printed sample obtained by different printing pressures. $L^{*} a^{*} b^{*}$ values were also converted to the HEX system (Nazar et al., 2017).

Microscopy of printed elements and measurements of the line width was performed through an Olympus BX51 
microscope. Obtained images were used for in-software measurements of the width of printed lines, both in positive and in negative. Line measurements were performed at a magnification of 200x, and images of the chosen typographic elements were taken at a magnification of 100x. Five measurements were performed on each print. The $200 \mu \mathrm{m}$ and $80 \mu \mathrm{m}$ lines in positive and negative were measured.

\section{Results and discussion}

\section{Bekk smoothness of papers}

The results of the smoothness measurements are presented in Figure 2. All papers except paper A displayed the smoothness under $3.2 \mathrm{~s}$, which is typical for uncoated papers. Paper A displayed average smoothness of $54.72 \mathrm{~s}$. Standard deviation of smoothness measurement for paper A was 7.01, and papers B-E displayed minimal standard deviations of measurements $(<0.18)$.

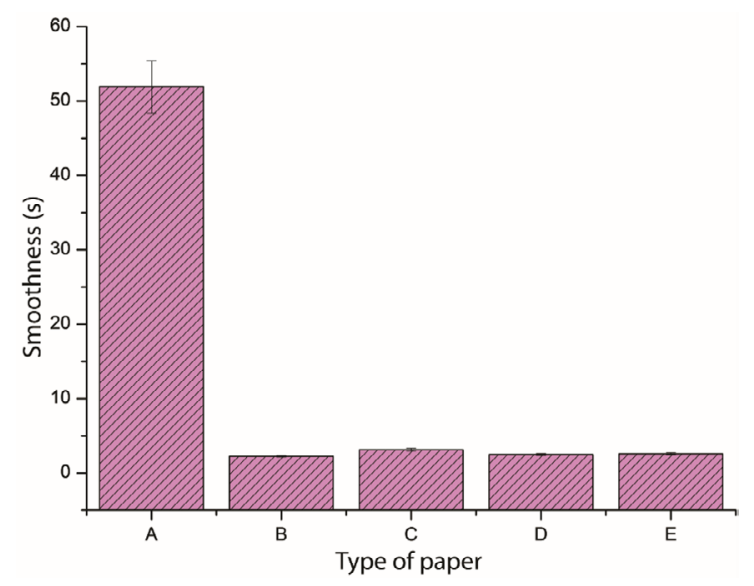

» Figure 2: Bekk smoothness of different recycled paper surfaces

Higher smoothness of paper A compared to other papers means that the printing plate will have to deform less during the engagement in the printing process, and the deformation of the printed elements should therefore be less pronounced than on other papers. Furthermore, the adjustment of the printing pressure on rough papers would be crucial for the optimization of the print's qualitative properties.

\section{Colorimetric measurements}

The colorimetric properties of the prints (CIE L*a*b* values) are presented in Table 2. $L^{*}, a^{*}$, and $b^{*}$ coordinates of the Pantone $363 \mathrm{U}$ ink are 50.91,-24.88, and 24.05, respectively. Letters A-E present the used papers, and numbers 1,2 , and 3 present the varied printing pressures $-50 \mathrm{~N}, 150 \mathrm{~N}$, and $400 \mathrm{~N}$, respectively.

\section{Table 2}

Colorimetric properties of prints obtained by PANTONE $363 \mathrm{U}$ on different recycled papers and by different printing pressure

\begin{tabular}{c|c|c|c|c}
\hline & & $\mathbf{1}$ & $\mathbf{2}$ & $\mathbf{3}$ \\
\hline \multirow{4}{*}{ A } & $L^{*}$ & $54.81 \pm 0.18$ & $51.62 \pm 0.24$ & $52.16 \pm 0.41$ \\
\cline { 2 - 5 } & $a^{*}$ & $-24.18 \pm 0.22$ & $-25.57 \pm 0.23$ & $-26.76 \pm 0.17$ \\
\cline { 2 - 5 } & $b^{*}$ & $19.53 \pm 0.13$ & $20.82 \pm 0.15$ & $22.19 \pm 0.16$ \\
\hline \multirow{4}{*}{ B } & $L^{*}$ & $57.43 \pm 0.44$ & $49.65 \pm 0.35$ & $48.45 \pm 0.37$ \\
\cline { 2 - 5 } & $a^{*}$ & $-18.89 \pm 0.19$ & $-23.96 \pm 0.17$ & $-23.68 \pm 0.14$ \\
\cline { 2 - 5 } & $b^{*}$ & $19.96 \pm 0.17$ & $22.43 \pm 0.19$ & $21.08 \pm 0.18$ \\
\hline \multirow{4}{*}{ C } & $L^{*}$ & $59.05 \pm 0.32$ & $50.85 \pm 0.44$ & $46.55 \pm 0.45$ \\
\cline { 2 - 5 } & $a^{*}$ & $-15.61 \pm 0.16$ & $-21.32 \pm 0.13$ & $-23.03 \pm 0.22$ \\
\cline { 2 - 5 } & $b^{*}$ & $15.51 \pm 0.12$ & $19.28 \pm 0.17$ & $19.36 \pm 0.21$ \\
\hline \multirow{4}{*}{$\mathbf{D}$} & $L^{*}$ & $50.31 \pm 0.48$ & $42.38 \pm 0.41$ & $40.89 \pm 0.37$ \\
\cline { 2 - 5 } & $a^{*}$ & $-8.21 \pm 0.11$ & $-15.31 \pm 0.22$ & $-16.06 \pm 0.23$ \\
\cline { 2 - 5 } & $b^{*}$ & $15.14 \pm 0.16$ & $17.11 \pm 0.20$ & $15.72 \pm 0.19$ \\
\hline \multirow{4}{*}{ E } & $L^{*}$ & $44.21 \pm 0.33$ & $40.95 \pm 0.34$ & $38.68 \pm 0.28$ \\
\cline { 2 - 5 } & $a^{*}$ & $-7.12 \pm 0.09$ & $-10.72 \pm 0.10$ & $-12.72 \pm 0.14$ \\
\cline { 2 - 5 } & $b^{*}$ & $17.56 \pm 0.10$ & $16.99 \pm 0.14$ & $15.63 \pm 0.11$ \\
\hline
\end{tabular}

The values in Table 2 indicate that the prints on paper A have the most similar values to Pantone $363 \mathrm{U}$. All prints on paper $\mathrm{A}$, together with $\mathrm{B} 1$ and $\mathrm{C} 1$ samples have an increased $L^{*}$ value compared to the original, which means that the colors are lighter. D1 and E1 samples have the lowest value of $a^{*}$, which means that these colors are shifting away from green color. In general, papers $D$ and $E$ present with the highest deviations from the original color. Deviations of each individually printed color from Pantone $363 \mathrm{U}$ are displayed in Figure 3, presented in the HEX system. HEX value for Pantone $363 \mathrm{U}$ is 57844D. LAB color values converted to HEX color system are listed in Table 3.

\section{Table 3}

$L^{*} a^{*} b *$ values of printed ink on each recycled paper in HEX color system

\begin{tabular}{c|c|c|c|c|c}
\hline & A & B & C & D & E \\
\hline $\mathbf{1}$ & $5 F 8 \mathrm{E} 60$ & 719366 & 799672 & $707 \mathrm{C} 5 \mathrm{D}$ & $656 \mathrm{C} 4 \mathrm{~B}$ \\
\hline $\mathbf{2}$ & 548756 & $54814 \mathrm{E}$ & $5 \mathrm{~B} 8357$ & $526 \mathrm{~B} 47$ & 576544 \\
\hline $\mathbf{3}$ & 548854 & $517 \mathrm{E} 4 \mathrm{E}$ & $4 \mathrm{D} 794 \mathrm{C}$ & $4 \mathrm{C} 6846$ & $4 \mathrm{D} 6141$ \\
\hline
\end{tabular}

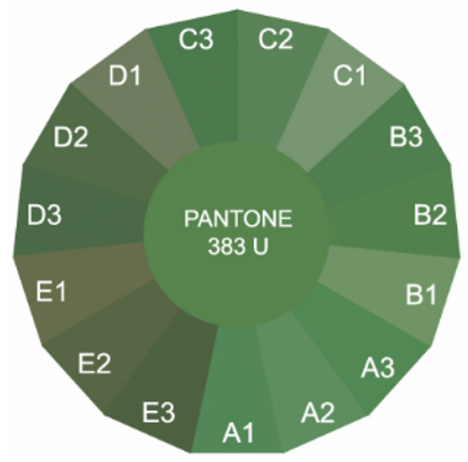

» Figure 3: $L A B$ values of printed ink on each paper in HEX color system 


\section{Width of the printed lines}

The width of the lines of $200 \mu \mathrm{m}$ was measured as a representative of the thickest printed line, and $80 \mu \mathrm{m}$ as a representative of the thinnest printed line. The results of the $200 \mu \mathrm{m}$ line's width obtained by the varied printing pressure in positive are presented in Figure 4.

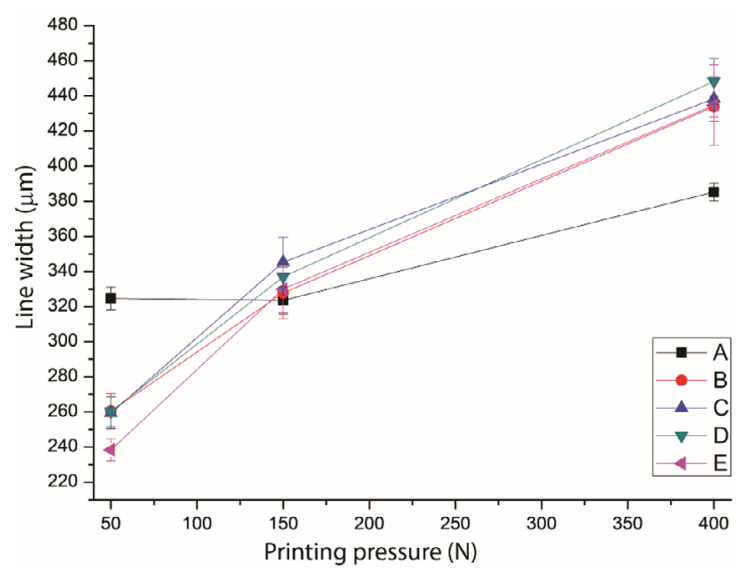

» Figure 4: Width of the printed $200 \mu \mathrm{m}$ line on each paper-positive

Observing Figure 4, one can conclude that paper $\mathrm{A}$ is the most constant in comparison to the others in terms of the changes in line width when different printing pressure is applied. This stability can be related to the smoothness of the paper. Since paper A is the smoothest paper among the five used types, the printed ink retains on the surface. Due to the lower smoothness of other papers, printing ink more easily penetrates the pores of the paper (Varepo et al., 2017). Therefore, when the printing pressure is increased, significant changes in the width of the printed lines will occur. At the lowest pressure, the flexible printing plate deforms the least. As the printing pressure increases, the printing plate deforms more, which increases the contact area with the printing substrate, i.e. the printed line becomes thicker. On all papers, the $200 \mu \mathrm{m}$ line at a minimal pressure of $50 \mathrm{~N}$ has a width higher than $200 \mu \mathrm{m}$. Although at low pressure there is almost no printing plate deformation, the values for the line width on all papers are higher than they should be because papers are not coated and printed ink is absorbed into and spread on the paper. Therefore, special compensation curves (Tomašegović et al., 2014) should be applied when producing the printing plate intended for print on uncoated recycled papers. A visual comparison of $200 \mu \mathrm{m}$ lines printed on papers $A, B$, and $D$ can be seen in Figure 5 .

Results presenting the measured width of $200 \mu \mathrm{m}$ line in negative on each recycled paper after varying the printing pressure can be seen in Figure 6.

For lines in negative, increased printing pressure will result in the thinner line. Only on paper B, a $200 \mu \mathrm{m}$ line in the negative can be printed at the lowest pressure of $50 \mathrm{~N}$. At the lowest pressure, the line on paper A presents a value lower than $200 \mu \mathrm{m}$, while other papers display higher line widths. Increasing the pressure on papers reduces the width of the line, but paper $A$ is stable in terms of line width decrease at $150 \mathrm{~N}$ pressure. $200 \mu \mathrm{m}$ line can also be achieved on the print on papers $B, D$, and $E$ when choosing the printing pressure of $150 \mathrm{~N}$. Significant decrease of the line width at $400 \mathrm{~N}$ happens due to the expressed deformation of the elastomeric printing plate during the engagement. The deformation increases the contact area between the printing plate and the substrate. In general, when increasing the printing pressure from $50 \mathrm{~N}$ to $400 \mathrm{~N}$ on chosen substrates, the line width in negative falls by about a quarter of the original value. A visual comparison of 200 $\mu \mathrm{m}$ printed lines in negative can be seen in Figure 7.
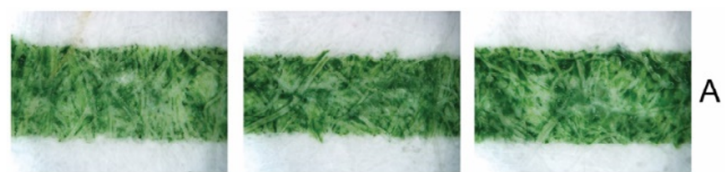

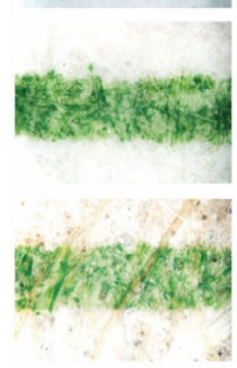

$50 \mathrm{~N}$
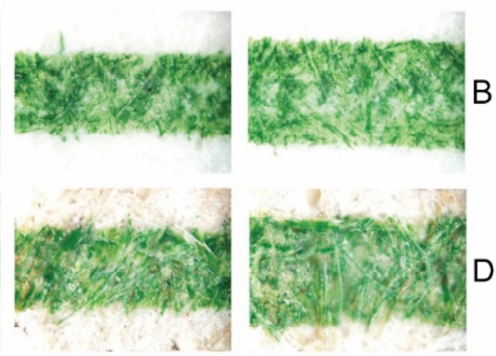

$150 \mathrm{~N}$

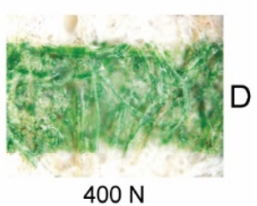

„ Figure 5: Microscopic images of $200 \mu \mathrm{m}$ line (positive) on papers $A, B$, and $D$, magnification of $200 x$

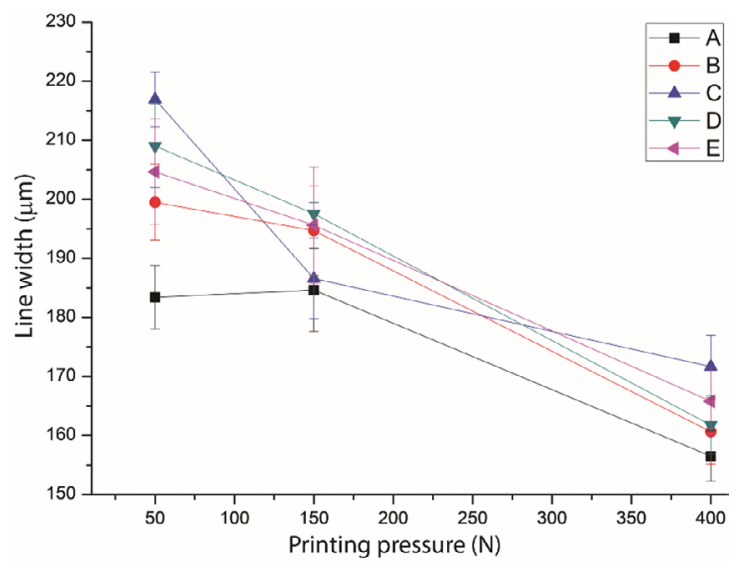

» Figure 6: Width of the printed $200 \mu \mathrm{m}$ line on each paper-negative

Results presenting the measured width of $80 \mu \mathrm{m}$ line printed in positive on each recycled paper after varying the printing pressure can be seen in Figure 8.

On all papers, printed lines are wider than $80 \mu \mathrm{m}$. Paper $\mathrm{D}$ presents with the thinnest line at the lowest pressure 
(50 N), but it is twice as wide as it should be. The line on paper $\mathrm{A}$ is significantly thicker than on other papers but has the most constant line width when increasing the printing pressure compared to other papers. On paper $B$, the line presents the smallest change in width when increasing the pressure from $150 \mathrm{~N}$ to $400 \mathrm{~N}$, while on paper $D$, the increase of line width is most expressed. Presented results indicate that a specific compensation curve, different than one intended for printing on paper $A$, should be applied in the printing plate production process when choosing papers B-E as printing substrates. After the application of the specific compensation curves, printing pressure should be minimized to achieve a fine printed line of the desired width.

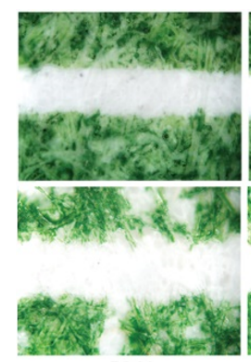

$50 \mathrm{~N}$

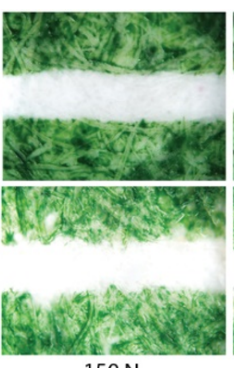

$150 \mathrm{~N}$

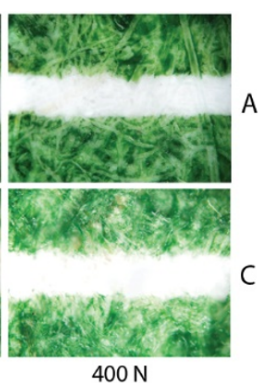

$400 \mathrm{~N}$
» Figure 7: Microscopic images of $200 \mu \mathrm{m}$ line (negative) on papers $A, B$, and $D$, magnification of $200 x$

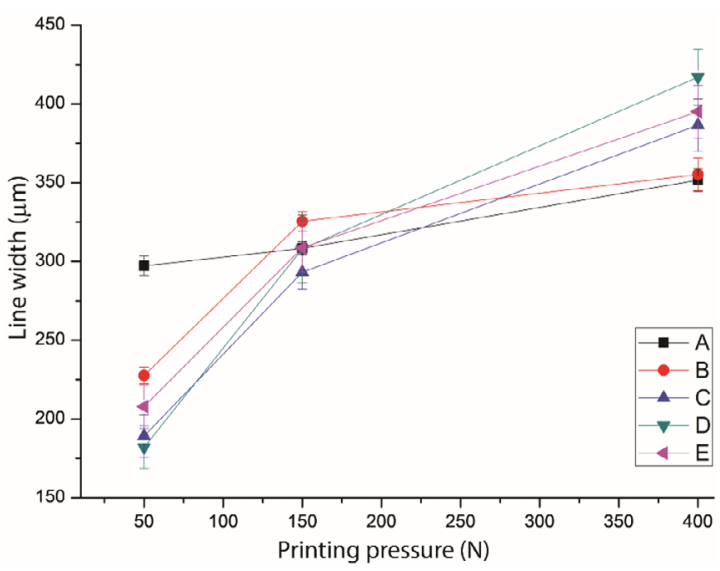

" Figure 8: Width of the printed $80 \mu \mathrm{m}$ line on each paper-positive

Changes in the width of $80 \mu \mathrm{m}$ line printed in negative on each recycled paper after varying the printing pressure can be seen in Figure 9.

On paper A, at a pressure of $50 \mathrm{~N}$, the lines of $80 \mu \mathrm{m}$ in negative are slightly wider than they should be but are the thinnest compared to the lines on other papers. As the line pressure increases up to $400 \mathrm{~N}$, the lines become expressively thinner, as expected.

When observing the diagrams presenting the lines in positive (Figures 4 and 8 ), it can be noticed that paper $A$ initially (when applying the pressure of $50 \mathrm{~N}$ ) presents with wider lines compared to other papers. Similarly, lines printed on paper $\mathrm{A}$ in negative at $50 \mathrm{~N}$ are thinner than on other papers (Figures 6 and 9). This happens because paper $\mathrm{A}$ is much smoother than the others. On paper A, printing ink spreads mostly on the surface, even when using the minimal printing pressure, since the pores on the paper are not as large as on other papers. Deviations of line width on all papers are expressed because the papers are uncoated. In the negative, the deviations in the width of each specific line are generally higher than for the lines in positive. The lines in positive are thin, i.e. their surface is small, so the deformation is numerically lower than for the lines in negative, where the printing surfaces are much larger and the "closing" of the line due to the deformation of the printing plate is more pronounced and visible (Mahović Poljaček et al., 2014). Nevertheless, the $80 \mu \mathrm{m}$ lines in the positive have a significantly higher value than $80 \mu \mathrm{m}$. They are similar in value to $200 \mu \mathrm{m}$ lines. This indicates that most of the tested papers are not suitable for printing very fine elements in positive. However, $80 \mu \mathrm{m}$ line in negative can be achieved on all papers when choosing the adequate printing pressure.

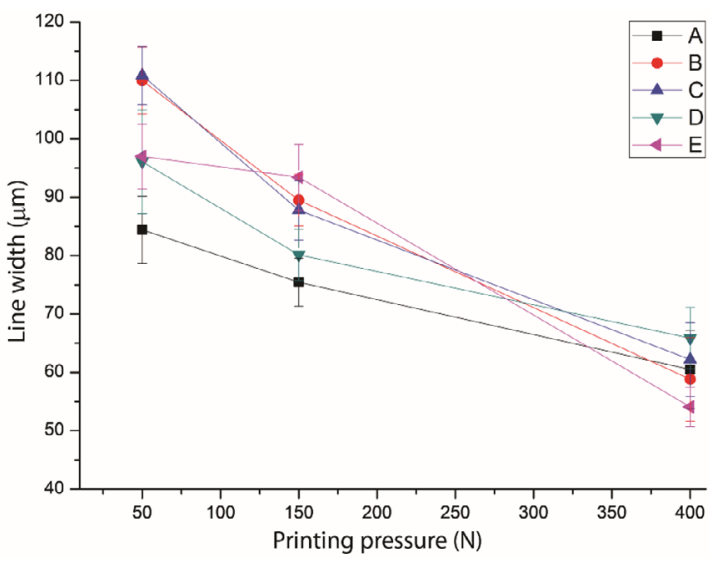

» Figure 9: Width of the printed $80 \mu \mathrm{m}$ line on each paper-negative

\section{Microscopy of typographic printed elements and determination of color contrast}

Microscopic images of typographic elements (18 pt) in positive and negative are presented in Figures 10 and 11 , respectively.

In Figure 10, it is visible that paper A presents with the sharpest edges of printed elements at all pressures, and printed elements on this paper have the smallest change in width when the printing pressure changes. The center of the printed letters is the palest - the element edges are outlined-which is usual for the flexographic print due to the printing plate deformation. This happens because 
of the different pressure distribution on the finer printing elements on the printing plate during the engagement. Printed elements on all papers are the widest and most filled when applying a printing pressure of $400 \mathrm{~N}$, which reduces the kerning, and some letters could overlap. This is specifically visible on the prints on papers $C$ and $E$.

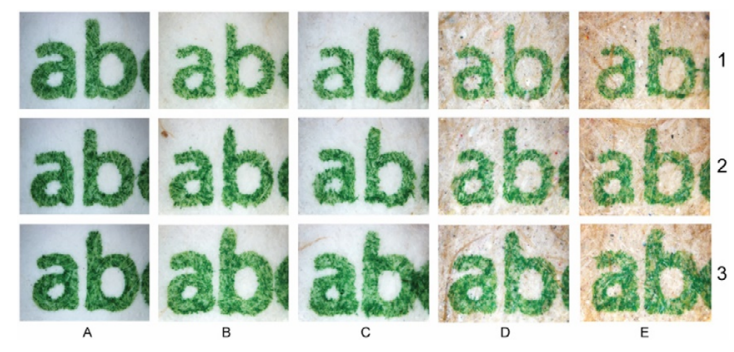

» Figure 10: Microscopic images of fine printed elements in positive, magnification of $100 x$

Printing pressure of $50 \mathrm{~N}$ on papers $\mathrm{C}, \mathrm{D}$, and $\mathrm{E}$ results with partially illegible text in the negative (Figure 11). Because of the low printing pressure, the printing plate is not able to deform enough to adjust to the rough printing substrate and the full-tone printed area does not have enough coverage. By increasing the pressure to $150 \mathrm{~N}$ the text becomes more legible on all papers, but it is also thinner. Under the pressure of $400 \mathrm{~N}$, due to the deformation of the printing plate, parts of the letters that are already very thin begin to disappear. It is visible that paper A presents with the "cleanest" lines.

It can be concluded that recycled papers $D$ and $E$ are not suitable for the typographic printed elements in negative of higher quality. For papers, A-C, printing pressure should be increased from the standard value of $150 \mathrm{~N}$ to achieve the optimal line edge definition and legibility of the typographic elements.

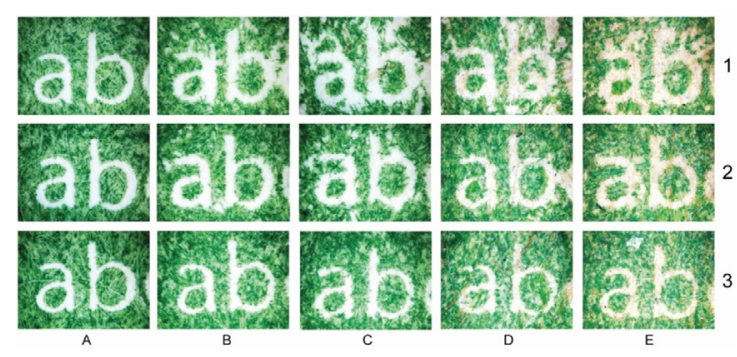

» Figure 11: Microscopic images of fine printed elements in positive, magnification of $100 x$

To determine whether the prints meet the recommendations on the applicability of images and text for the visually impaired (Chung \& Bernard, 2018), the color contrasts of the typographic elements on all papers were measured against the background color (Table 4). Various accessibility standards and guidelines prescribe specific difference in luminance between two adjacent colours or overlaid colours, but commonly indorsed minimal contrast ratio for 18 px texts is 4:1 (Vischeck, 2002).

\section{Table 4}

Color contrast values concerning the background color (paper) for typographic elements:

\begin{tabular}{c|c|c|c|c|c}
\hline & A & B & C & D & E \\
\hline $\mathbf{1}$ & 4.41 & 3.65 & 3.63 & 3.12 & 3.93 \\
\hline $\mathbf{2}$ & 4.41 & 3.85 & 3.89 & 3.44 & 4.06 \\
\hline $\mathbf{3}$ & 3.75 & 3.89 & 4.11 & 3.47 & 4.10 \\
\hline
\end{tabular}

Minimal color contrast (for a font size of 18pt) was met on all prints except for prints on paper $D$. For this reason, paper $D$ would not be suitable as a substrate for commercial use for the Pantone $363 \mathrm{U}$ ink used in this experiment. The highest contrast values were achieved on paper A.

\section{Conclusion}

In this research, the optimization of the print quality on different recycled papers was performed. The choice of biodegradable materials as printing substrates for packaging in this experimental work is an optimal solution for the environment. However, there is a difference between recycled papers in terms of their properties, that influence the printability and print quality. For example, their natural shade and rough, porous surface influence the colorimetric properties of the print and ink absorption and spreading.

The results of this research have shown that specific shade of the papers can influence the colorimetric properties of the print to a significant extent, regardless of the increased printing pressure which enables the transfer of more printing ink to the printing substrate. Moreover, the smoothness of the paper is directly related to ink spreading on the surface of the print. Smoothest paper $A$ is most constant in terms of the printed line width when the printing pressure is increased. Fine lines in positive $(80 \mu \mathrm{m})$ were printed significantly too wide on all papers, even when the lowest pressure of $50 \mathrm{~N}$ was chosen. This means that special compensation curves should be applied in the printing plate production process to achieve the adequate width of such fine elements. When printing fine elements in positive, printing pressure should be minimized. Fine lines in negative can be correctly printed on all selected papers by carefully adjusting the printing pressure and achieving the optimal elastic deformation of the printing plate. Furthermore, increased printing pressure can result in the illegibility of the typographic elements in positive, and inadequate pressure in negative could result in unclear edges or disappearing of the printed typographic elements. All recycled papers except paper 
D met the minimal color contrast required for the applicability of images and text for the visually impaired.

It can be concluded that most recycled papers used in this experimental work are not suitable for printing very fine elements in positive when choosing flexography as a printing technique. Fine elements in negative can be achieved by carefully adjusting the printing pressure. Since the principles of the sustainable design recommend the minimal needed amount of materials used for the (packaging) product, the consumption of the printing ink should be decreased as much as possible. Therefore, if the maximal possible quality of the print on a recycled paper is crucial, only important fine elements should be designed and printed in negative. Printing pressure should be carefully adjusted to each paper to transfer enough printing ink to achieve legibility, but at the same time to not cause extensive deformation of other printed elements.

\section{References}

Aydemir, C. (2016) A study on the printability properties of alkali-sized recycled papers. Science and Engineering of Composite Materials. 23 (5), 565-571. Available from: doi: 10.1515/secm-2013-0266

Bates, I., Plazonić, I., Radić Seleš, V. \& Barbarić-Mikočević, Ž. (2020) Determining the quality of paper substrates containing triticale pulp for printing industry. Nordic Pulp and Paper Research Journal. 35 (2), 272-278. Available from: doi: 10.1515/npprj-2020-0009

Chung, S. T. L. \& Bernard, J. B. (2018) Bolder print does not increase reading speed in people with central vision loss. Vision Research. 153, 98-104. Available from: doi: 10.1016/j.visres.2018.10.012

Cigula, T., Tomašegović, T. \& Hudika, T. (2019) Effect of the paper surface properties on the ink transfer parameters in offset printing. Nordic Pulp and Paper Research Journal. 34 (4), 540-549. Available from: doi: 10.1515/npprj-2019-0018

Dahlbo, H., Poliakova, V., Mylläri, V., Sahimaa, O. \& Anderson, R. (2018) Recycling potential of post-consumer plastic packaging waste in Finland. Waste Management. 71, 52-61. Available from: doi: 10.1016/j.wasman.2017.10.033

El-Sherif, H. M., Nasser, A. M., Hussin, A. I., Abd El-Wahab, H., Ghazy, M. B. M. \& Elsayed, A. E. (2019) Tailoring of mechanical properties and printability of coated recycled papers. Polymer Bulletin. 76 (6), 2965-2990. Available from: doi: 10.1007/s00289-018-2515-7

IGT Testing Systems (2016) F1 Basic. Available from: https://www.igt.nl/product/f1-basic/ [Accessed: 26th September 2020].

Ivanković, A., Zeljko, K., Talić, S. \& Lasić, M. (2017) Biodegradable Packaging in Food Industry. Jornal of Food Safety and Food Quality, 68 (2), 23-52. Available from: doi: 10.2376/0003-925X-68-26
Izdebska, J., Żołek-Tryznowska, Z. \& Świętoński, A. (2015) Correlation between plastic films properties and flexographic prints quality. Journal of Graphic Engineering and Design. 6 (2), 19-25.

Kaiser, K., Schmid, M. \& Schlummer, M. (2017) Recycling of Polymer-Based Multilayer Packaging: A Review. Recycling. 3 (1), 1-26. Available from: doi: 10.3390/recycling3010001

Mahović Poljaček, S., Tomašegović, T., Cigula, T., Gojo, M. \& Milčić, D. (2014) Formation of the Printing Elements in the Photopolymer Material Used in Flexography. Key Engineering Materials. 611-612, 883-891. Available from: doi: 10.4028/www.scientific.net/KEM.611-612.883

Marrez, D. A., Abdelhamid, A. E. \& Darwesh, O. M. (2019) Eco-friendly cellulose acetate green synthesized silver nano-composite as antibacterial packaging system for food safety. Food Packaging and Shelf Life. 20, 100302. Available from: doi: 10.1016/j.fpsl.2019.100302

Miljković, P., Valdec, D. \& Matijević, M. (2018) The impact of printing substrate on dot deformation in flexography. Tehnički Vjesnik. 25 (2), 509-515. Available from: doi: 10.17559/TV-20170710152140

Mohamed, R. M. \& Yusoh, K. (2015) A Review on the Recent Research of Polycaprolactone (PCL). Advanced Materials Research. 1134, 249-255. Available from: doi: 10.4028/www.scientific.net/amr.1134.249

Moustafa, H., Youssef, A. M., Darwish, N. A. \& AbouKandil, A. I. (2019) Eco-friendly polymer composites for green packaging: Future vision and challenges. Composites Part B: Engineering. 72, 16-25. Available from: doi: 10.1016/j.compositesb.2019.05.048

Mraović, M., Muck, T., Pivar, M., Trontelj, J. \& Pleteršek, A. (2014) Humidity Sensors Printed on Recycled Paper and Cardboard. Sensors. 14 (8), 13628-13643. Available from: doi: 10.3390/s140813628

Nazar, M., Khan, R. Q., Perveen, M. \& Khan, W. Q. (2017) Web branding harmonizer: Need of color harmonies and its solution in website development. In: 2017 International Conference on Infocom Technologies and Unmanned Systems (Trends and Future Directions) (ICTUS). 18-20 December 2017, Dubai, United Arab Emirates. IEEE, pp. 346-350. Available from: doi: 10.1109/ICTUS.2017.8286030

Pivnenko, K., Eriksson, E. \& Astrup, T. F. (2014) Waste paper for recycling: Overview and identification of potentially critical substances. Waste Management. 45, 134-142. Available from: doi: 10.1016/j.wasman.2015.02.028

Tomašegović, T., Mahović Poljaček, S., Cigula, T., Gojo, M. \& Milčić, D. (2014) Correlation between the lams and printing element area on the flexographic printing plate. In: Urbas, R. (ed.) Proceedings of 7th Symposium of Information and Graphic Arts Technology, 5-6 June 2014, Ljubljana, Slovenia. University of Ljubljana, Ljubljana. pp. 43-49. 
Tomašegović, T., Beynon, D., Claypole, T. \& Poljaček, S. M. (2016) Tailoring the properties of deposited thin coating and print features in flexography by application of UV-ozone treatment. Journal of Coatings Technology Research. 13, 815-828. Available from: doi: 10.1007/s11998-016-9794-4

Tomašegović, T., Mahović Poljaček, S., Strižić Jakovljević, M. \& Urbas, R. (2020) Effect of the Common Solvents on UV-Modified Photopolymer and EPDM Flexographic Printing Plates and Printed Ink Films. Coatings. 10 (2), 136. Available from: doi: 10.3390/coatings10020136

Varepo, L. G., Brazhnikov, A. Y., Volinsky, A. A., Nagornova, I. V. \& Kondratov, A. P. (2017) Control of the offset printing image quality indices. Journal of Physics: Conference Series. 858 (1), 12038. Available from: doi: 10.1088/1742-6596/858/1/012038

Vischeck (2002) About Vischeck. Available from: http://www.vischeck.com/vischeck/ [Accessed: 26th September 2020].

Wienke, A., Hoffmann, G.-A., Koch, J., Jäschke, P., Overmeyer, L. \& Kaierle, S. (2020) Ablation and functionalization of flexographic printing forms using femtosecond lasers for additively manufactured polymer-optical waveguides. Procedia CIRP. 94, 846-849. Available from: doi: 10.1016/j.procir.2020.09.112

X-Rite (2018) eXact Standard Handheld Spectrophotometer. Available from: https://www.xrite. com/categories/portable-spectrophotometers/ exact [Accessed: 26th September 2020]

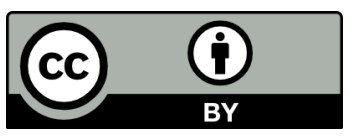

(C) 2021 Authors. Published by the University of Novi Sad, Faculty of Technical Sciences, Department of Graphic Engineering and Design. This article is an open access article distributed under the terms and conditions of the Creative Commons Attribution license 3.0 Serbia (http://creativecommons.org/licenses/by/3.0/rs/). 